\title{
CT cystography for evaluation of augmented bladder perforation: be safe and know the limitations
}

\author{
Boaz Karmazyn ${ }^{1}$
}

Received: 24 September 2015 / Accepted: 2 November 2015 / Published online: 27 November 2015

(C) Springer-Verlag Berlin Heidelberg 2015

Sir,

I have read with interest the review paper of Breen et al. [1] on imaging of augmented bladder. The authors justly centered on imaging of perforated bladder, the most dreadful complication. We agree with the authors that the study of choice is CT cystography.

We would like to add a few important points related to the safety of the study and its limitations. The filling of the bladder should be performed using low pressure technique. The augmented bladder compliance may decrease with time and there are case reports on perforation of the augmented bladder at about $50 \mathrm{~cm} \mathrm{H}_{2} \mathrm{O}[2,3]$. In our practice, the bag of contrast is hung at $20 \mathrm{~cm}$ above the table level. In addition, the bladder filling is discontinued if the child complains of any discomfort or pain.

Bladder perforation may be sealed by the time the CT cystography is performed. In our experience, only $74 \%$ of patients demonstrated contrast extravasation with $\mathrm{CT}$ cystography. Therefore, radiologists should be aware of secondary signs of bladder perforation such as moderate or large pelvic fluid and pneumoperitoneum that cannot be explained by other pathology (e.g., perforated bowel, recent surgery or large pneumomediastinum) [4]. In patients with increased or new pelvic fluid with no other imaging findings of bladder perforation, US-guided taping of the fluid with high creatinine level is diagnostic for perforation.

\section{Compliance with ethical standards}

Conflicts of interest The author reports no conflicts of interest.

\section{References}

1. Breen M, Phelps A, Estrada C et al (2015) The role of imaging in pediatric bladder augmentation. Pediatr Radiol 45:1440-1447

2. Ehdaie B, Mason MD, Gray M et al (2013) Bladder perforation in augmentation cystoplasty during urodynamic investigation: a case report and review of the literature. J Pediatr Urol 9:e102-e106

3. Blok BF, Al Zahrani A, Capolicchio JP et al (2007) Postaugmentation bladder perforation during urodynamic investigation. Neurourol Urodyn 26:540-542

4. Karmazyn B, Gurram S, Marine MB et al. (2015) Is CT cystography an accurate study in the evaluation of spontaneous perforation of augmented bladder in children and adolescents? J Pediatr Urol. doi: 10.1016/j.jpurol.2015.04.024

Boaz Karmazyn

Bkarmazy@iupui.edu

Department of Radiology and Imaging Sciences,

Riley Hospital for Children,

Indiana University School of Medicine,

705 Riley Hospital Drive, Room 1053, Indianapolis, IN 46202, USA 